\title{
$\alpha$-Helix peptides designed from EBV-gH protein display higher antigenicity and induction of monocyte apoptosis than the native peptide
}

\author{
Mauricio Urquiza $\cdot$ Johanna Melo-Cardenas · Tatiana Guevara • \\ Ignacia Echeverria • Isabel C. Rodriguez • Magnolia Vanegas • \\ Mario Amzel • Manuel E. Patarroyo
}

Received: 18 February 2010/Accepted: 30 April 2010/Published online: 16 May 2010

(c) The Author(s) 2010. This article is published with open access at Springerlink.com

\begin{abstract}
We tested the hypothesis that stabilizing $\alpha$ helix of Epstein-Barr virus gH-derived peptide 11438 used for binding human cells will increase its biological activity. Non-stable $\alpha$-helix of peptide 11438 was unfolded in an entropy-driven process, despite the opposing effect of the enthalpy factor. Adding and/or changing amino acids in peptide 11438 allowed the designing of peptides 33207, 33208 and 33210; peptides 33208 and 33210 displayed higher helical content due to a decreased unfolding entropy change as was determined by AGADIR, molecular dynamics and circular dichroism analysis. Peptides 33207, 33208 and 33210 inhibited EBV invasion of peripheral blood mononuclear cells and displayed epitopes more similar to native protein than peptide 11438; these peptides could be useful for detecting antibodies induced by native $\mathrm{gH}$ protein since they displayed high reactivity with antiEBV antibodies. Anti-peptide 33207 antibodies showed higher reactivity with EBV than anti-peptide 11438 antibodies being useful for inducing antibodies against EBV. Anti-peptide 33210 antibodies inhibit EBV invasion of epithelial cells better than anti-peptide 11438 antibodies.
\end{abstract}

M. Urquiza - J. Melo-Cardenas · T. Guevara .

I. C. Rodriguez $\cdot$ M. Vanegas - M. E. Patarroyo

Fundacion Instituto de Inmunologia de Colombia,

Bogotá, Colombia

M. Urquiza · T. Guevara - M. E. Patarroyo

Universidad Nacional de Colombia, Bogotá, Colombia

I. Echeverria · M. Amzel

Biophysics and Biophysical Chemistry, Johns Hopkins

University, Baltimore, USA

M. Urquiza ( $\bowtie)$

3855 Health Sciences Dr, MC 0820, San Diego, CA, USA

e-mail: murquiza@ucsd.edu
Peptide 33210 bound to normal T lymphocytes and Raji cells stronger than peptide 11438 and also induced apoptosis of monocytes and Raji cells but not of normal $\mathrm{T}$ cells in a similar way to EBV-gH. Peptide 33210 inhibited the monocytes' development toward dendritic cells better than EBV and peptide 11438. In conclusion, stabilizing the $\alpha$ helix in peptides 33208 and 33210 designed from peptide 11438 increased the antigenicity and the ability of the antibodies induced by peptides of inhibiting EBV invasion of host cells.

Keywords gH - gp85 - Entropy - Antibody · Configurational entropy $\cdot$ Dendritic cells

$\begin{array}{ll}\text { Abbreviations } \\ \text { EBV } & \text { Epstein-Barr virus } \\ \text { PBMCs } & \text { Peripheral blood mononuclear cells } \\ \text { GM-CSF } & \begin{array}{l}\text { Granulocyte-monocyte colony stimulating } \\ \text { factor } \\ \text { RP-HPLC }\end{array} \\ & \begin{array}{l}\text { Reverse phase-high performance liquid } \\ \text { chromatography }\end{array} \\ \text { CD } & \text { Circular dichroism } \\ \text { TFE } & \text { 2,2,2-Trifluoroethanol } \\ \Delta H & \text { Enthalpy change } \\ \Delta S & \text { Entropy change } \\ \Delta G & \text { Gibbs free energy change }\end{array}$

Introduction

Epstein-Barr virus (EBV), one of the most common worldwide human viruses, is capable of inducing infectious mononucleosis (Henle et al. 1968) and it has also been 
implicated in developing several malignant tumors such as nasopharyngeal carcinoma (Huang et al. 1974; Raab-Traub et al. 1987), Burkitt's lymphoma (De-The and Zeng 1982), and the X-associated lymphoproliferative disease (Harada et al. 1982). EBV is also critical in immune compromised patients receiving allograft or having acquired immune deficiency syndrome, sometimes leading to host death (Montagnier et al. 1984; Pelicci et al. 1986; Yarchoan et al. 1986).

EBV can infect monocytes, B lymphocytes and epithelial cells mainly through EBV proteins gp350/220 and gp42/gH/gp25 (gp42/gH/gL) complex which binds to host cell proteins CD21 (CR2), MHC class II and the integrins $\alpha \mathrm{v} \beta 6$ and $\alpha \mathrm{v} \beta 8$ (Chesnokova et al. 2009; Li 1997; Nemerow et al. 1989; Spriggs et al. 1996; Tanner 1987; Wang et al. 1998). The gH protein (also known as gp85) can be used as an alternative EBV ligand in CD21 and MHC class II-negative epithelial cells and is actively involved in virus and cell membrane fusion (Miller and Hutt-Fletcher 1988; Haddad and Hutt-Fletcher 1989; Molesworth et al. 2000; Wang et al. 1998). The $\mathrm{gH}$ protein is part of a heterodimer complex $(\mathrm{gH} / \mathrm{gL})$ which is highly expressed on EBV produced from B cells and the heterotrimer complex (gH/gpL/ gp42) which is highly expressed on EBV produced from epithelial cells (Wang et al. 1998). The trimer:dimer ratio is key for EBV cell tropism; EBV from B cells tends to infect easily epithelial cells whereas EBV from epithelial cells efficiently infects B lymphocytes (Borza and HuttFletcher 2002). EBV is not able to fuse with B cells or bind to epithelial cells in the absence of the $\mathrm{gH}$ or when the heterotrimer complex is blocked with an anti-gp42 monoclonal antibody (F-2-1), but does not affect EBV-binding to B lymphocytes (Borza and Hutt-Fletcher 2002; Haddad and Hutt-Fletcher 1989, 1988), indicating the importance of $\mathrm{gH}$ protein in EBV attaching to epithelial cells and fusion to B cells.

It has been also reported that EBV-gH/gL complex is able to interact with monocyte cells. When these monocytes were cultured with granulocyte-monocyte colony stimulating factor (GM-CSF) and interleukin-4 (IL4) this interaction was able of inhibit the development of monocytes towards dendritic cells by delaying the down-regulation of CD14 marker and by inducing apoptosis (Li et al. 2002).

There are two cell-binding regions identified in this protein; peptides (11435 and 11438) from these regions specifically bind to host cells and inhibit EBV invasion of peripheral blood lymphocytes (PBLs) (Urquiza et al. 2004). Antibodies induced by these peptides were also able of inhibit EBV invasion of PBLs, but presented low reactivity against EBV by ELISA. These suggest that lower biological activity of peptides compared with the native protein is due to high configurational entropy. Modifications in amino acid sequences can diminish configurational peptide entropy by stabilizing its structure. The aim of this work was to increase the peptide's biological activity by changing or adding some amino acids that diminish peptide's entropy.

\section{Materials and methods}

Peptide synthesis

Peptides were synthesized by solid-phase multiple peptide system (Houghten 1985; Jeener et al. 1979). MBHA resin (0.7 meq/g); t-Boc amino acid, and low-high cleavage techniques were used. Peptides were analyzed by MALDITOF mass spectrometry and reverse phase-high performance liquid chromatography (RP-HPLC) (data not shown). Peptides were reconstituted in sterile PBS pH 7.4.

\section{AGADIR analysis}

Helical content of peptides were calculated using the prediction algorithm developed by Serrano's group (AGADIR) with an amide group at the C-terminal and an acetyl group at the $\mathrm{N}$-terminal region. The conditions used were: temperature at $278^{\circ} \mathrm{K}$, ionic strength 0.1 and $\mathrm{pH} 7.0$ (Muñoz and Serrano 1997).

\section{Circular dichroism analysis}

Circular dichroism (CD) spectra were made for peptides 11438, 33207, 33208 and 33210 to estimate $\alpha$-helix content percentage and stability. Peptides were prepared in aqueous $30 \%$ TFE solution at $100 \mu \mathrm{M}$ concentration. CD spectra were taken on a 1-cm-long quartz cell on a Jasco J-810 thermostated spectrophotometer (Provencher and Glockner 1981). CD spectra resulted from the average of four scans obtained by collecting data at $0.1-\mathrm{nm}$ intervals from 260 to $190 \mathrm{~nm}$ at $20^{\circ} \mathrm{C}$. The $\alpha$-helical content was estimated from the molar ellipticity at $222 \mathrm{~nm}$ by using the following equation:

$\% \alpha$-helix $=(-[\Theta] 222 \mathrm{~nm}+3000) / 39000$

where $[\Theta]$ is molar ellipticity (Provencher and Glockner 1981).

The thermodynamic analysis of an $\alpha$-helix unfolding/ folding transition was performed by Van't Hoff analysis. In brief, $\alpha$-helix content percentage estimated from absorption at $222 \mathrm{~nm}$, at different temperatures $(T)$, lead to calculating affinity constants $(K)$ for unfolding folding transition at these temperatures. The $(1 / T)$ versus $\operatorname{Ln}(K)$ curve gave a straight line in which, according to the following equation: 
$\operatorname{Ln}(K)=-\Delta H / R(1 / T)+\Delta S / R$.

The slope is unfold/fold transition enthalpy change over $R$-constant and the intercept is unfold/fold transition entropy change over $R$-constant.

Modeling and molecular dynamics of peptides

The peptide helices were built using the program QUANTA based on primary sequence using the helical angles phi -60 and -50 psi, the side chains were accommodated by using the Karplus rotamer library in order to reduce high-energy interactions that destabilized the model. These molecules were submerged in a water box containing $11 \times 11 \times 16$ water molecules. Then 5,000 steps of minimization were performed by steepest descendent at an initial temperature $100^{\circ} \mathrm{K}$ and then increased to reach the final temperature of $310^{\circ} \mathrm{K}$. The molecular dynamics was ran at a constant temperature, pressure and number of molecules, using the program CHARMM (http://www.charmm.org), the unfolding of the peptide was followed by molecular dynamics during 200,000 steps of $0.01 \mathrm{ps}$ each one. Data from energy, structure and trajectory were collected every 500 steps. The final analysis was based on the structure and number of hydrogen bonds that were present in the peptide over a period of $100 \mathrm{ps}$ by using distribution curves.

Immunization protocol

Two New Zealand rabbits were subcutaneously immunized with $500 \mu \mathrm{g}$ of peptides $11438,332207,33208,33210$ or EBV physically mixed with $150 \mu \mathrm{g}$ of $\mathrm{T}$ helper epitope FISEAIIHVLHSR (Prieto et al. 1995) and emulsified with $250 \mu \mathrm{l}$ Freund's complete adjuvant (500 $\mu \mathrm{l}$ final volume). Then rabbits were boosted on days 20,40 and 60 , with the same antigen dose but emulsified in Freund's incomplete adjuvant. Blood was drawn 20 days after the second and third doses.

\section{Rabbit antibody isolation}

Rabbit sera were diluted four times with $60 \mathrm{mM}$ acetate buffer ( $\mathrm{pH} 4.0$ ); the $\mathrm{pH}$ was raised to 4.5 by adding $\mathrm{NaOH}$ $0.1 \mathrm{~N} .25 \mu \mathrm{l} / \mathrm{ml}$ caprylic acid was added and stirred for $30 \mathrm{~min}$. Samples were then centrifuged at $10,000 \times g$ for $30 \mathrm{~min}$, and the supernatant was separated. A 1/10 volume of $10 \times$ PBS was added to the obtained supernatant and the $\mathrm{pH}$ adjusted to 7.4 with $\mathrm{NaOH} 0.1 \mathrm{~N}$. The immunoglobulin fraction was precipitated with $0.35 \mathrm{~g} / \mathrm{ml}$ ammonium sulfate overnight at $4^{\circ} \mathrm{C}$. The pellet was separated at $5,000 \times g$ for $15 \mathrm{~min}$ at $4^{\circ} \mathrm{C}$ and suspended in PBS. The immunoglobulin solution was extensively dialyzed with PBS. The isolated protein concentration was determined by the Bradford test $(100-170 \mu \mathrm{g} / \mathrm{ml})$ and antibody activity by ELISA (Delves 1997).

Antibodies reactivity detected by ELISA

ELISA-plates with 96-wells were coated with peptides $11438,33207,33208$ or 33210 , at different concentrations $(10-0.6 \mu \mathrm{g} / \mathrm{ml})$ diluted in PBS and incubated overnight at $4^{\circ} \mathrm{C}$. Plates were then washed four times with PBS containing $0.05 \%$ Tween20 (PBS-T). Non-specific binding sites were blocked with $200 \mu \mathrm{l} 4 \%$ non-fat dry milk in PBS-T for $2 \mathrm{~h}$ at $37^{\circ} \mathrm{C}$. After washing as described above, $100 \mu$ of rabbit sera serial dilution $(1 / 100,1 / 51,200)$ was added and incubated for $1 \mathrm{~h}$ at $37^{\circ} \mathrm{C}$. After washing, peroxidase-conjugated anti-rabbit antibody (VECTOR) was diluted 1:5,000 in blocking buffer and $100 \mu \mathrm{l}$ was added to each well. The plates were incubated for $1 \mathrm{~h}$ at $37^{\circ} \mathrm{C}$. After washing, $100 \mu \mathrm{l}$ peroxidase substrate $\left(3,3^{\prime}, 5,5^{\prime}\right.$-tetramethyl benzidine-SIGMA) was added to the plates. To stop the reaction, $\mathrm{H}_{2} \mathrm{SO}_{4}(0.1 \mathrm{~N})$ was added to each well and absorbance was measured at $420 \mathrm{~nm}$. The assay was performed in triplicate and considered valid only when the triplicates' coefficient of variation was lower than $10 \%$.

Antibody titers were calculated as the minimum dilution at which the antiserum recognized the antigen.

\section{PCR amplification of EBV DNA}

EBV-containing supernatant used for EBV and B lymphocyte interaction studies was obtained from the American Type Culture Collection (ATCC Catalogue number VR-1492). DNA from normal PBMCs was obtained by phenol-chloroform extraction and ethanol precipitation. DNA was dissolved in $20 \mu \mathrm{l}$ of TE buffer [ $10 \mathrm{mM}$ Tris$\mathrm{HCl}(\mathrm{pH} 8.0), 1 \mathrm{mM}$ EDTA], $0.5 \mathrm{mg} / \mathrm{ml}$ final concentration (Chen et al. 2002). PCR was performed in $20 \mu \mathrm{l}$ of reaction mixture containing $10 \mathrm{mM}$ Tris- $\mathrm{HCl}(\mathrm{pH} \mathrm{8.3)}$, $50 \mathrm{mM} \mathrm{KCl}, 1.5 \mathrm{mM} \mathrm{MgCl}_{2}$, and each of the following $200 \mu \mathrm{M}$ deoxyribonucleotide triphosphate, $0.1-0.5 \mu \mathrm{g}$ of template DNA, each primer at $0.5 \mu \mathrm{M}$, and 1.0 unit of Taq polymerase. Previously reported primers (3) were used to specifically amplify EBV DNA: 5'-TTCATCACCGTCG CTGACT- $3^{\prime}$ upstream sequence and $5^{\prime}$-ACCGCTTA CCACCTCCTCT- $3^{\prime}$ downstream sequence. These primers specifically amplified a 300-bp DNA fragment from EBV (+) cells (Raji or B95-8), but not EBV (-) cells (erythrocyte fraction, or HeLa cells). PCR conditions consisted of 35 cycles at $95^{\circ} \mathrm{C}$ for $30 \mathrm{~s}, 55^{\circ} \mathrm{C}$ for $30 \mathrm{~s}$, and $72^{\circ} \mathrm{C}$ for $30 \mathrm{~s}$ in a 9600 thermal cycler (PerkinElmer Life Sciences). The amplified fragment was separated on $2.0 \%$ agarose gels; the PCR product was visualized on a Molecular Imager FX (Bio-Rad). 
Neutralizing antibodies assay

Serial dilutions of anti-peptide sera were incubated with EBV for $30 \mathrm{~min}$ at $37^{\circ} \mathrm{C}$. Then $5 \times 10^{3}$ HEK293 cells were added in a final volume of $40 \mu \mathrm{l}$ and incubated for $4 \mathrm{~h}$ at $37^{\circ} \mathrm{C}$. Cells were washed twice with HBSS $1 \times$ and heated at $100^{\circ} \mathrm{C}$ for $10 \mathrm{~min}$. DNA was suspended in $20 \mu \mathrm{l}$ of ultra pure water and $2 \mu \mathrm{l}$ were used for PCR amplification as described above.

\section{EBV infectivity inhibition assay}

PBMCs or HEK 293 cells were culture at a density of $2 \times 10^{5}$ cells/100 $\mu$ in RPMI 1640 , supplemented with $10 \%$ heat-inactivated serum, $100 \mathrm{U} / \mathrm{ml}$ penicillin, $100 \mu \mathrm{g} / \mathrm{ml}$ streptomycin, $0.4 \mu \mathrm{g} / \mathrm{ml}$ cyclosporine $\mathrm{A}$, and $5 \mathrm{mM} \mathrm{CaCl}{ }_{2}$ and incubated with $30 \mu \mathrm{lEBV}$-supernatant for $30 \mathrm{~min}$ at $37^{\circ} \mathrm{C}$ in 5\% $\mathrm{CO}_{2}$ atmosphere. Then $70 \mu \mathrm{l}$ RPMI- 1640 medium was added and the samples were incubated for $16 \mathrm{~h}$ at $37^{\circ} \mathrm{C}$ in $5 \%$ $\mathrm{CO}_{2}$ atmosphere. After incubation, cells were washed three times with RPMI-1640 medium (FBS free). The peptide's effect on EBV-interaction with PBMCs or HEK293 cells was determined by pre-incubating these cells with 27,13 , or $7 \mu \mathrm{M}$ of each peptide for $15 \mathrm{~min}$ at $37^{\circ} \mathrm{C}$ immediately preceding the EBV-interaction with host cells (Urquiza et al. 2004).

\section{Peptide's binding assay}

PBMC from a normal donor and Raji and Ramos cell lines were incubated with peptides 11438, 33207, 33208 or 33210 at different concentrations $(1,3$ or $10 \mu \mathrm{M})$ in FACS buffer (PBS, BSA $1 \%$, sodium azide $0,05 \%$ ). After $1 \mathrm{~h}$ of incubation at $4{ }^{\circ} \mathrm{C}$, cells were washed and incubated with anti-peptide serum produced in rabbits at a $1 / 200$ dilution for $40 \mathrm{~min}$ at $4^{\circ} \mathrm{C}$. Only PBMCs were additionally stained with antibodies anti CD3-PerCP, CD19-PE and CD14-APC conjugated antibodies. Unbound antibodies were washed and cells were incubated with mouse anti-rabbit IgG-FITC and propidium iodide to exclude death cells. After 40 min of incubation, cells were washed and resuspended in $200 \mu \mathrm{L}$ of FACS buffer. Samples were run in a FACScan and data analysis was performed by using CellQuest software. To determine the peptide binding, first we calculated the mean fluorescence intensity ratio (MFIR) of the cells incubated with the peptide and its anti-peptide rabbit-serum divided by the mean fluorescence intensity of the cells incubated only with the anti-peptide rabbit-serum. Then, we calculated the percentage of binding based on 11438-peptide binding as $100 \%$.

Human monocyte isolation

PBMCs were obtained from healthy donor, collected in heparin-treated sterile tubes by sedimentation on Ficoll-
Hypaque gradients. PBMCs thus obtained were washed three times with RPMI-1640, spun at $300 \times g$ for $7 \mathrm{~min}$ at room temperature. Cell count and viability was determined by trypan blue staining (GIBCO). $2 \times 10^{6}$ cells $/ \mathrm{ml}$ were cultured in RPMI 1640 medium supplemented with $10 \%$ heat-inactivated FBS, $100 \mathrm{U} / \mathrm{ml}$ penicillin, $100 \mu \mathrm{g} / \mathrm{ml}$ streptomycin and were allowed to adhere to a 24-well tissue culture plate for $4 \mathrm{~h}$ at $37^{\circ} \mathrm{C}$ with $5 \% \mathrm{CO} 2$ atmosphere. For removing non-adherent cells, confluent monolayers were washed once with RPMI 10\% FBS.

\section{EBV invasion}

EBV used for studies was obtained from the American Type Culture Collection (ATCC catalogue no. VR-1492). Confluent monolayers of cells were cultured with $7.2 \mathrm{nM}$ recombinant GM-CSF (Biosource) and $6.7 \mathrm{nM}$ recombinant IL4 (Biosource). These cells were culture in presence of $40 \mu \mathrm{l}$ of EBV $(100 \times)$ or $10.4 \mu \mathrm{M}$ of peptide (11438, 33207,33208 or 33210 ) and incubated for 3 days at $37^{\circ} \mathrm{C}$ with $5 \% \mathrm{CO}_{2}$ atmosphere. Monocytes were harvested with PBS-EDTA $0.5 \mathrm{nM}$ by flushing three times and washed twice with PBS-EDTA $0.5 \mathrm{nM}$, spun at 2,000 rpm for 5 min and stained with CD14-FITC conjugated (Pharmigen) 1/100 dilution for $20 \mathrm{~min}$. Cells were washed once with PBS-EDTA $0.5 \mathrm{mM}$ and suspended in $200 \mu \mathrm{l}$ of PBS-EDTA. Fluorescence intensity was monitored with a FACScan flow cytometer (Becton-Dickinson). This experiment was performed by duplicated and tested with six different volunteers given similar results.

\section{Peptide's cytotoxicity assay}

PBMC and Raji cells were culture with peptides 11438, 33207,33208 or 33210 at different concentrations $(1,3$ or $10 \mu \mathrm{M}$ ) in RPMI supplemented with FBS $10 \%$. After $3 \mathrm{~h}$ of incubation at $37^{\circ} \mathrm{C}$, cells were washed and resuspended in Annexin buffer 1X, Annexin V FITC conjugated and PI for $30 \mathrm{~min}$ at $4^{\circ} \mathrm{C}$. PBMCs were additionally stained with anti-CD3 and anti-CD14 antibodies. Then, cells were suspended in $100 \mu \mathrm{l}$ of Annexin buffer $1 \times$ and run in a FACScan.

\section{Results}

Peptides having theoretically more stable $\alpha$-helix were designed from peptide 11438 by using AGADIR

Peptide 11438 from EBV-gH contains a host human cellbinding sequence; this peptide is able to inhibit EBV invasion of B lymphocytes and to induce antibodies recognizing native protein; but its biological activity is lower 
than native protein. This peptide belongs to a protein region, which has been predicted having a high content of $\alpha$-helix as determined by GOR software (Garnier et al. 1996) and as it has previously been published (Omerovic et al. 2005). The CD spectrum of peptide 11438 dissolved in PBS with 30\% TFE displayed two minimum adsorptions at 208 and $222 \mathrm{~nm}$ that is characteristic of $\alpha$-helix (Fig. 1b). The peptide's helical content (determined by using absorption at $222 \mathrm{~nm}$ ) increased from 5.02 to $24.55 \%$ in 0 and $30 \%$ of TFE, respectively (Table 1). This indicated that peptide 11438 tended to be an $\alpha$-helix but this structure was not stable in aqueous solution and was easily distorted.

The theoretical helical content calculated for peptide 11438 in $\mathrm{pH} 7.0$, ionic strength 0.1 and at $278^{\circ} \mathrm{K}$ temperature was $0.83 \%$ by using the approach developed by Serrano's group (AGADIR analysis) (Bax and Davis 1985; Houghten 1985; Rance et al. 1983; Tam et al. 1983). Nterminal or C-terminal truncated peptides were analyzed by the same approach for determining the ability of each amino acid from peptide 11438 sequence to stabilize or distort the $\alpha$-helix structure. It was found that peptide's helical content was very low in part due to ${ }^{4} \mathrm{P}$ and betabranched residues ${ }^{14} \mathrm{VTMT}^{17}$ that could distort the helix at the $\mathrm{N}$-terminal and C-terminal region, respectively (data not shown). Taking into account this analysis, the ${ }^{5}$ NLKDMFSRA $^{13}$ sequence was used as template for designing new peptides that in theory could display a higher helical content than native sequence. Three different groups of peptides were designed either by adding amino acids at the C-terminal (Group 1), at the C-terminal after ${ }^{13} \mathrm{Ala}$ (Group 2) or at the N-terminal before ${ }^{5}$ Asn (Group 3) for inducing one theoretical $\alpha$-helix turn; in other words four residues having high probability of building one turn of $\alpha$-helix (and also create intra-peptide interactions to stabilize the helix) were included considering that the most difficult part of $\alpha$-helix folding process is the induction of the first $\alpha$-helix turn. Basic amino acids, Arg and Lys, were added at the C-terminal and acid amino acids Asp and Glu
Table 1 Helical content of peptides 11438 and its analogs

\begin{tabular}{llcl}
\hline Peptide & \multicolumn{3}{l}{$\%$ Helical content } \\
\cline { 2 - 4 } & $0 \%$ TFE & $5 \%$ TFE & $30 \%$ TFE \\
\hline 11438 & 5.02 & 5.34 & 24.55 \\
33207 & 2.96 & 2.96 & 10.75 \\
33208 & 9.86 & 11.38 & 40.39 \\
33210 & 6.48 & 7.73 & 27.63 \\
\hline
\end{tabular}

were added at the $\mathrm{N}$-terminal to stabilize the $\alpha$-helix dipole taking into account that the $\mathrm{C}$-terminal region and the $\mathrm{N}$ terminal region of the $\alpha$-helices are often capped with a positively charged amino acid, such as lysine and by a negatively charged amino acid, such as glutamic acid, respectively, in order to neutralize this helix dipole.

The designed peptide sequences having the highest calculated percentage of helical content appear in Fig. 1a. Only one peptide sequence from each group was selected for synthesis. These were NLKDMFSRAVTMTAASRKRAE (named peptide 33207); FVFNLKDMFSRANRK RKA, (named 33210) and MEDDYNLKDMFSRAVTM (named peptide 33208), were selected from the first, second and third group, respectively. Theoretical saline bridges were added at the $\mathrm{N}$-terminal $(3 \mathrm{D}-7 \mathrm{~K})$ in peptide 33208 or C-terminal (21R-25E) in peptide 33207. We expect that the modified regions in peptides 33207,33208 and 33210 will be non-immunogenic considering that most of these regions are built with charged amino acids that in general have been reported not involved in interactions with antibodies because the energetic cost for binding.

The theoretical $\alpha$-helix of peptides 33207,33208 and 33210 were more stable than the helix of peptide 11438 as determined by molecular dynamics

The $\alpha$-helix of peptides $11438,33207,33208$ and 33210 were built hydrated and minimized at $310^{\circ} \mathrm{K}$ by using QUANTA program; then the $\alpha$-helix stability was studied
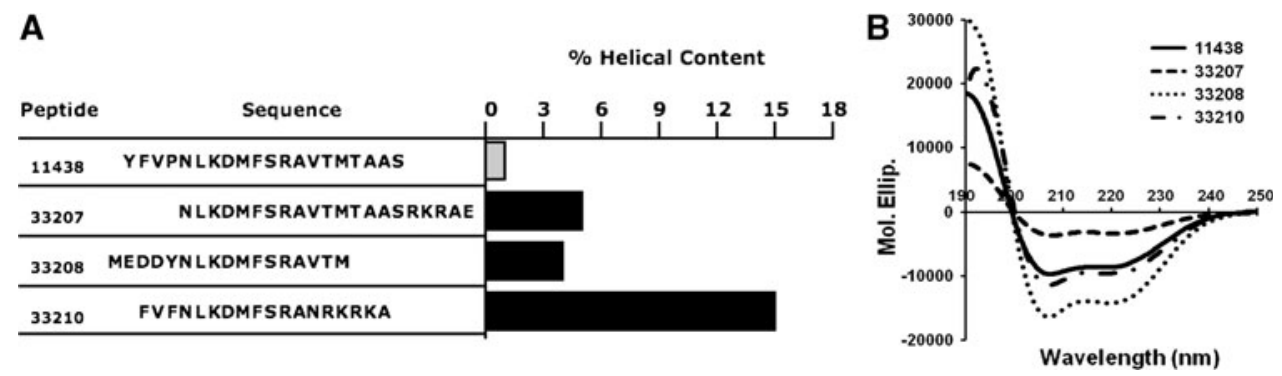

Fig. 1 Helical content and circular dichroism analysis performed in EBV-gH-derived peptides. a Peptide 11438 was modified by adding or deleting amino acids at $\mathrm{C}$ - and N-terminal regions and the helical content was calculated by AGADIR analysis. The sequence of peptide 11438 is shown in the gray bar. b Circular dichroism of peptides selected from each group (33207, 33208 and 33210 from groups 1, 2 and 3 , respectively) and peptide 11438 were dissolved in PBS with $30 \%$ TFE; the spectra were made on a JASCO spectrometer. The $X$ axis shows wavelength in $\mathrm{nm}$ and the $Y$-axis molar ellipticity per residue 
by molecular dynamics using CHARMM, quantifying the mean number of hydrogen bonds that remains in the $\alpha$ helix at $0.0,0.5,1.0,1.5$ and $2.0 \mathrm{~ns}$ during the molecular dynamics of the peptide in water at $310^{\circ} \mathrm{K}$. The $\alpha$-helix of peptide 11438 presented 11 mean hydrogen bonds at $0 \mathrm{~ns}$; the helix of this peptide unfold rapidly presenting 4 mean hydrogen bonds at $0.5 \mathrm{~ns}$ and this helix was completely unfolded at $1 \mathrm{~ns}$. The helix of peptide 33207 presented 13 mean hydrogen bonds at $0.0 \mathrm{~ns}$; this helix was very stable showing that at $2.0 \mathrm{~ns}$ remains 8 mean hydrogen bonds. The helix of peptide 33208 presented 8 mean hydrogen bonds at $0.0 \mathrm{~ns}$; this helix begins to unfold from the $\mathrm{N}$ terminal region; at $1.0 \mathrm{~ns}$ it displayed 6 mean hydrogen bonds and at 2.0 ns displayed 3 mean hydrogen bonds. The helix of peptide 33210 presented 9 mean hydrogen bonds at $0.0 \mathrm{~ns}$; this helix began to unfold from the N-terminal region displaying 6 mean hydrogen bonds at 1.0 and at $2.0 \mathrm{~ns}$ displayed 5 mean hydrogen bonds. These data showed that $\alpha$-helix of peptides 33207, 33208 and 33210 unfold slowly compared with peptide 11438 suggesting that $\alpha$-helix of peptides 33207, 33208 and 33210 were more stable than the $\alpha$-helix peptide 11438 (Fig. 2).

Circular dichroism showed that peptides 33208 and 33210 displayed more stable $\alpha$-helix than peptide 11438 due to lower unfolding entropy change

Peptides 11438, 33207, 33208 and 33210 were synthesized and analyzed by $\mathrm{CD}$ in 0,5 and $30 \% \mathrm{TFE}$ at $25^{\circ} \mathrm{C}$; the helical content was determined by using absorption at $222 \mathrm{~nm}$ (Fig 1b). The four analyzed peptides increased helical content in line with increased TFE concentration. Peptides 33208 and 33210 displayed a higher helical content than peptide 11438 in 0,5 and $30 \%$ TFE. On the contrary peptide 33207 presented a lower helical content than native peptide 11438 (Table 1). The $222 \mathrm{~nm}$ absorption in CD spectra at different temperatures was used for determining equilibrium constants $(\mathrm{Ke})$ of folding/unfolding reaction considering
A

11438

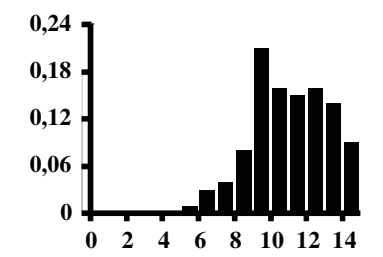

33207

33208

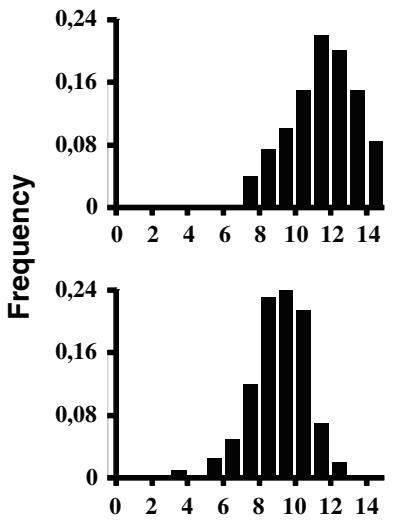

33210

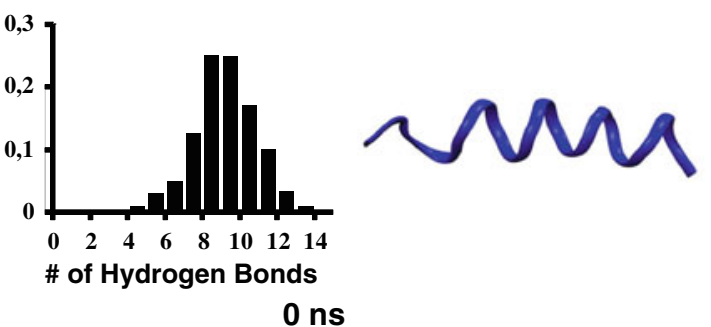

B
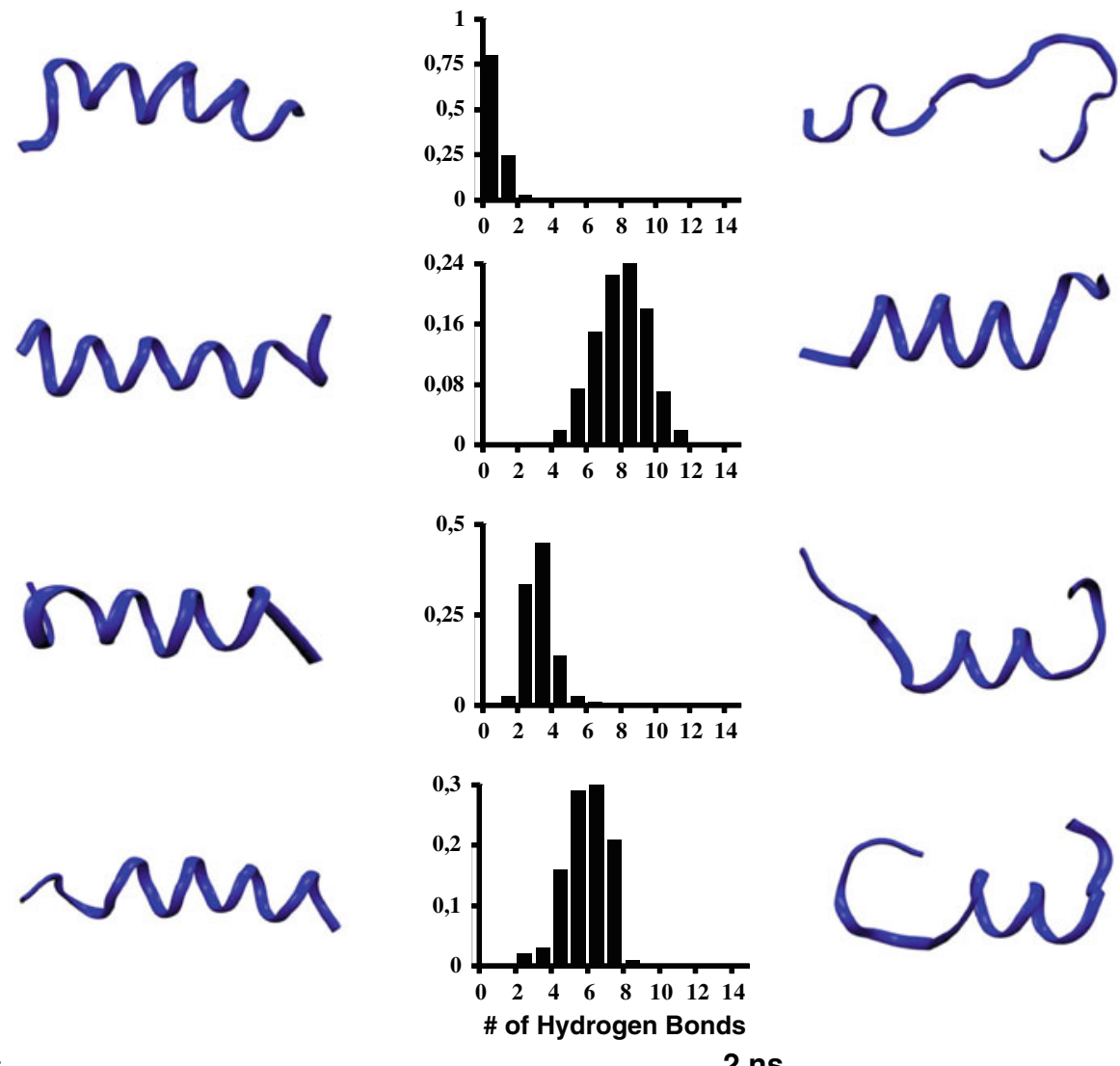

2 ns
Fig. 2 Molecular dynamics performed in peptides 11438, 33207, 33208 and 33210. The $\alpha$-helix of peptides 11438, 33207, 33208 and 33210 were built by using Quanta. After these peptides were hydrated and minimized the molecular dynamics were run during $2 \mathrm{~ns}$ at $310 \mathrm{~K}$ by using CHARMM. a Mean frequency of hydrogen bonds that are present in the peptide structure at $0.0 \mathrm{~ns}$. On the right side are shown the ribbon structures acquired by these peptides during the molecular dynamics, which were built by using VMD program. In $\mathbf{b}$ is shown the same as in a but at $2 \mathrm{~ns}$ 
Table $2 \alpha$-Helix thermodynamic folding parameters of peptide 11438 and its analogs

\begin{tabular}{lllll}
\hline Peptide & $\Delta G(\mathrm{~kJ} / \mathrm{mol})$ & $\Delta H(\mathrm{~kJ} / \mathrm{mol})$ & $T \Delta S(\mathrm{~kJ} / \mathrm{mol})$ & $R^{2}$ \\
\hline 11438 & -2.72 & 12.76 & 15.48 & 0.99 \\
33207 & -5.33 & 5.64 & 10.97 & 0.93 \\
33208 & -1.02 & 9.80 & 10.82 & 0.97 \\
33210 & -2.40 & 11.04 & 13.43 & 1.00 \\
\hline
\end{tabular}

two-state transition; the unfold stage is a random peptide conformation and fold stage $\alpha$-helix peptide conformation. $\Delta G$ of folding-unfolding was determined from $\Delta G=$ $-\mathrm{RTLn}(\mathrm{Ke}) ; \Delta H$ and $\Delta S$ of folding/unfolding reaction were determined from Ke at different temperatures by using Van't Hoff's equation (Table 2). Helical content for these four peptides $(11438,33207,33208$ and 33210) varied linearly in the studied temperature range, having square linear correlation coefficients between 0.93 and 1.00, displaying a negative slope and thereby showing that the $\alpha$-helix in these peptides unfolded when temperature was increased. $\operatorname{Ln}(K)$ versus $1 / T$ curve for these four peptides displayed negative slopes with square linear correlation coefficients between 0.94 and 0.99 supporting Van't Hoff's analysis (Table 2). Most of the molecules or the sequence of these four peptides tend to stay in an unfolded state (random conformation), according to $\Delta G$ determined above, but the helical content and the stability of the helix of peptide $33208(\Delta G=$ $-1.02 \mathrm{~kJ} / \mathrm{mol})$ and $33210(\Delta G=-2.40 \mathrm{~kJ} / \mathrm{mol})$ was higher than peptide $11438(\Delta G=-2.72 \mathrm{~kJ} / \mathrm{mol})$; on the contrary, the helical content and the helix stability of peptide 33207 $(\Delta G=-5.33 \mathrm{~kJ} / \mathrm{mol})$ was lower than peptide 11438 . The helix of these peptides tend to unfold due to a higher entropy of the unfolded state than the folded state; being higher for peptide $11438(T \Delta S=15.48 \mathrm{~kJ} / \mathrm{mol})$ than peptide 33207 $(T \Delta S=10.973 \mathrm{~kJ} / \mathrm{mol})$, peptide $33208(T \Delta S=10.973 \mathrm{~kJ} /$

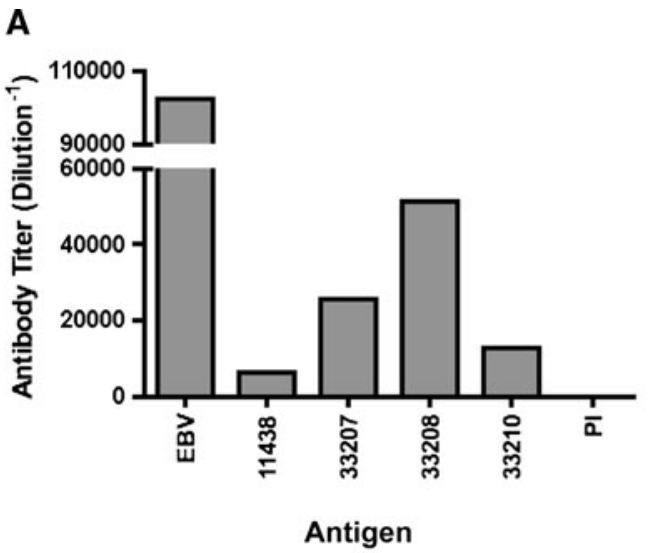

Fig. 3 Antigenicity and immunogenicity of peptides 11438, 33207, 33208 and 33210. Rabbits were immunized with EBV, 11438, 33207, 33208 or 33210 . After three immunizations polyclonal serum was obtained and tested by ELISA. a Anti-EBV antibodies were tested for mol) and peptide $33210(T \Delta S=13.43 \mathrm{~kJ} / \mathrm{mol})$. On the contrary, the enthalpy change opposes to unfolding of the helix of these peptides ( $\Delta H$ between 5.64 and $12.76 \mathrm{~kJ} / \mathrm{mol}$ ).

The higher $\alpha$-helix stability of the peptides 33208 and 33210 compared with peptide 11438 was due to lower entropy change of unfolding in spite of having lower enthalpy change of unfolding than peptide 11438. On the contrary, the lower $\alpha$-helix stability of the peptide 33207 than peptide 11438 is due to a lower enthalpy change of unfolding $(\Delta H=5.64 \mathrm{~kJ} / \mathrm{mol})$ in spite of a lower entropy change of unfolding compared with peptide 11438 . These data indicate that the modified peptides 33208 and 33210 were more prone to state as $\alpha$-helix than native peptide 11438 as a consequence of minor entropy change in foldunfold transition.

Peptides 33207, 33208 and 33210 displayed epitopes with higher reactivity with anti-EBV antibodies but no higher immunogenicity than peptide 11438

In order to determine whether or not amino acid changes on these peptides modified the epitopes that interact with the antibodies induced by EBV, the reactivity of peptides $11438,33207,33208$ and 33210 with anti-EBV was determined by using ELISA. The antibodies induced by EBV were able to recognize peptides 33207,33208 and 33210 with antibody titers of 25,600, 51,200 and 12,800, respectively, having higher reactivity than with peptide 11438 which showed an antibody titer of 6,400 (Fig. 3a). Anti-EBV antibodies did not recognize irrelevant peptide (data not shown).

Taking into account that analog peptides displayed higher reactivity with anti-EBV antibodies than peptide 11438, we were interested in determining how strong the reactivity of the antibodies induced by analog peptides with

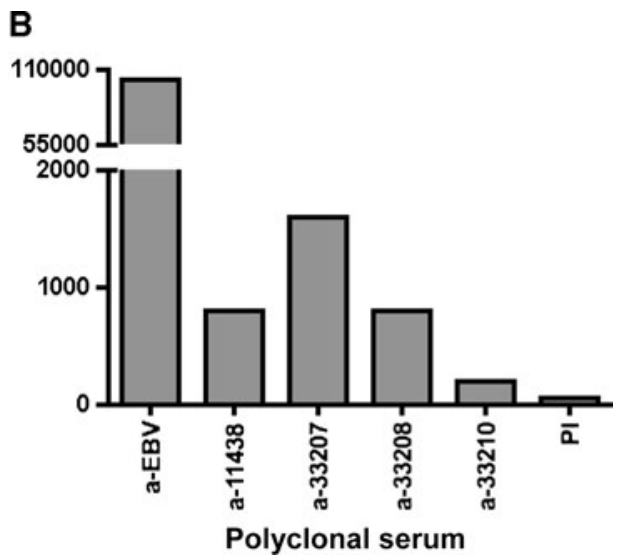

their reactivity against peptides to evaluate peptides' antigenicity. b Reactivity of anti-peptides antibodies was tested against EBV to evaluate peptide's immunogenicity. PI pre-immune sera 
EBV is compared with the reactivity of peptide 11438 . The immunogenicity of peptides was determined by the reactivity of antibodies induced by these peptides in recognizing EBV. Polyclonal sera were obtained by immunizing rabbits with peptides $11438,33207,33208$ or 33210 as described in "Materials and methods". The titers of the polyclonal sera against the respective peptide were higher than 100,000 (data not shown). Then the polyclonal serum was tested for its reactivity against EBV. The antibodies induced by peptides 11438 and 33208 presented similar reactivity against EBV with antibody titer of 800, antibodies induced by peptide 33210 presented lower reactivity with antibody titer of 200 and anti-33207 antibodies presented a higher reactivity in recognizing EBV with antibody titer of 1,600 (Fig. 3b).

Peptides 11438, 33207, 33208 and 33210 inhibited EBV invasion of host cells in vitro

It has been previously reported that peptide 11438 is able to inhibit EBV invasion of PBMCs (Urquiza et al. 2004). We tested whether or not the analog peptides designed were able to inhibit virus invasion. The results showed that analog peptides 33207,33208 and 33210 were able to inhibit EBV invasion of PBMCs in a similar manner than peptide 11438 in vitro at $27 \mu \mathrm{M}$ but not at 13 or $7 \mu \mathrm{M}$ as determined by PCR. Additionally taking into account that $\mathrm{gH}$ binds to epithelial cells, we tested the ability of these peptides in inhibiting the invasion of EBV by HEK293 cells. Peptide 11438 inhibited at all the concentrations tested (27, 13 and $7 \mu \mathrm{M}$ ). Peptides 33207 and 33210 inhibited at 27 and $13 \mu \mathrm{M}$, and peptide 33208 inhibited only at $27 \mu \mathrm{M}$. This indicates that sequence modifications performed in peptides 33207, 33208 and 33210 did not alter the ability of these peptides to block EBV invasion of PBMCs but there was a decrease in the ability of analogous peptides to block invasion of HEK293 cells (Fig. 4a).

EBV-binding inhibition assay was not performed using the $\mathrm{gH}$ protein directly considering that we do not have a quantitative test for detecting EBV-binding to host cells or the gH-complex.

Anti-peptide 33210 antibodies inhibit EBV invasion of epithelial cells better than anti-peptide 11438 antibodies

The capability of anti-peptide antibodies in inhibiting EBV invasion of epithelial cells was determined considering that $\mathrm{gH}$ protein can be used as an alternative EBV ligand in epithelial cells. HEK293 cells were selected for these experiments taking into account that previously it was demonstrated that EBV infects this cell line (Fingeroth 1999). EBV was incubated with serial dilutions of anti-
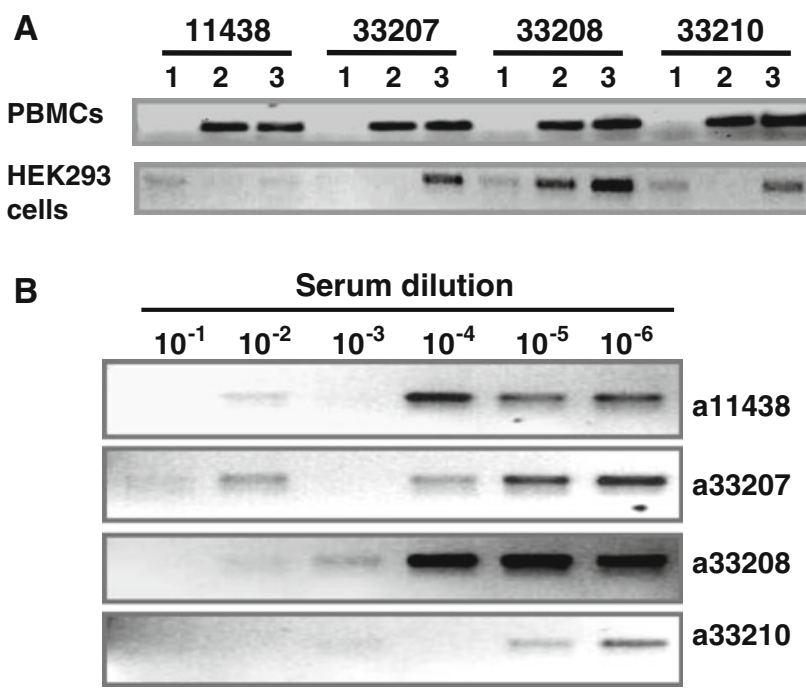

Fig. 4 Effect of peptides and anti-sera of peptides 11438, 33207, 33208 and 33210 in EBV invasion of host cells. a PBMCs and HEK293 cells were treated with EBV and peptides 11438, 33207, 33208 or 33210 at different concentrations: $127 \mu \mathrm{M}, 213 \mu \mathrm{M}$ or 3 $7 \mu \mathrm{M}$. After the incubation period DNA was isolated and PCR amplification of an EBV DNA fragment was performed. b Activity of anti-peptide sera at different dilutions in neutralizing EBV invasion of HEK293 cells

peptide antibodies then added to HEK cells; the EBVinfected cells were detected by PCR. It was found that antipeptide antibodies induced by 11438, 33207 and 33208 inhibited the EBV invasion of these cells up to rabbitserum dilutions of $10^{-3}$; anti-peptide 333210 antibodies inhibited up to serum dilution of $10^{-4}$ (Fig. 4b.). These results indicate that analog peptides 33207, 33208 and 33210 contain critical epitopes for induction of neutralizing antibodies; additionally, peptide 33210 induced more potent anti-EBV neutralizing antibodies than peptide 11438 .

Peptide 33210 showed higher binding activity to PBMC, Ramos and Raji cells than peptide 11438

Taking into account that peptide 11438 sequence belongs to the $\mathrm{gH}$ binding region we were interested in determining the binding of these peptides to different type of cells. Peptide 11438 bound to PBMC, Ramos and Raji cells as detected by flow cytometry. Taking peptide 11438 binding to these cells as $100 \%$ it was found that peptide 33210 displayed between 150 and $250 \%$ higher binding activity to PBMC and Raji cells than peptide 11438; it was not possible to detect differences in the binding of peptides 11438 , 33207 and 33208 to these cells as determined by flow cytometry, suggesting that peptides 11438, 33207 and 33208 have a lower binding affinity than peptide 33210 . The analysis performed in PBMC showed that peptide 
33210 preferentially bound to $\mathrm{T}$ cells $(\mathrm{CD} 3+)$ (Fig. 5a) compared to B cells (CD19) or monocytes (CD14). Interestingly, peptide 33210 increased CD3 positive cells in vitro.

Peptide 33210 inhibited the development of monocytes towards dendritic cells better than EBV

We asked whether gH-derived peptides inhibit the development of dendritic cells from precursor monocyte in the same manner as $\mathrm{gH}$ protein does as described by $\mathrm{Li}$ et al. (2002). Monocytes in presence of granulocyte-monocyte colony stimulating factor (GM-CSF) and interleukin-4 (IL4) mature towards dendritic cell; however, if these monocytes are simultaneously incubated with EBV they do not mature to dendritic cells as determined by the persistent expression of CD14 surface marker due to the interaction of gH with monocyte surface. GM-CSF and IL-4 exposed monocytes were incubated with peptides 11438, 33207, 33208,33210 or EBV to determine their capacity of regulating CD14 surface marker (detected by FACS analysis). These cells in presence of EBV displayed 62\% more CD14 positive cells than non-EBV-exposed cells peptides; in presence of peptides 11438,33207 or 33208 displayed $14.9,27$ or $13.5 \%$ more CD14 positive cells; respectively. Interestingly, these monocytes in presence of peptide 33210 showed $89.2 \%$ more CD14 positive cells than nonEBV-exposed cells and higher than native peptide 11438 or EBV, indicating that this peptide displayed a better effect on regulation of CD14 surface marker than peptide 11438 or EBV (Fig. 5b). In addition, it was determined that peptide 33210 induces IL12p70 production in monocytes cultured with GM-CSF and IL4 but not without these cytokines (personal communication).
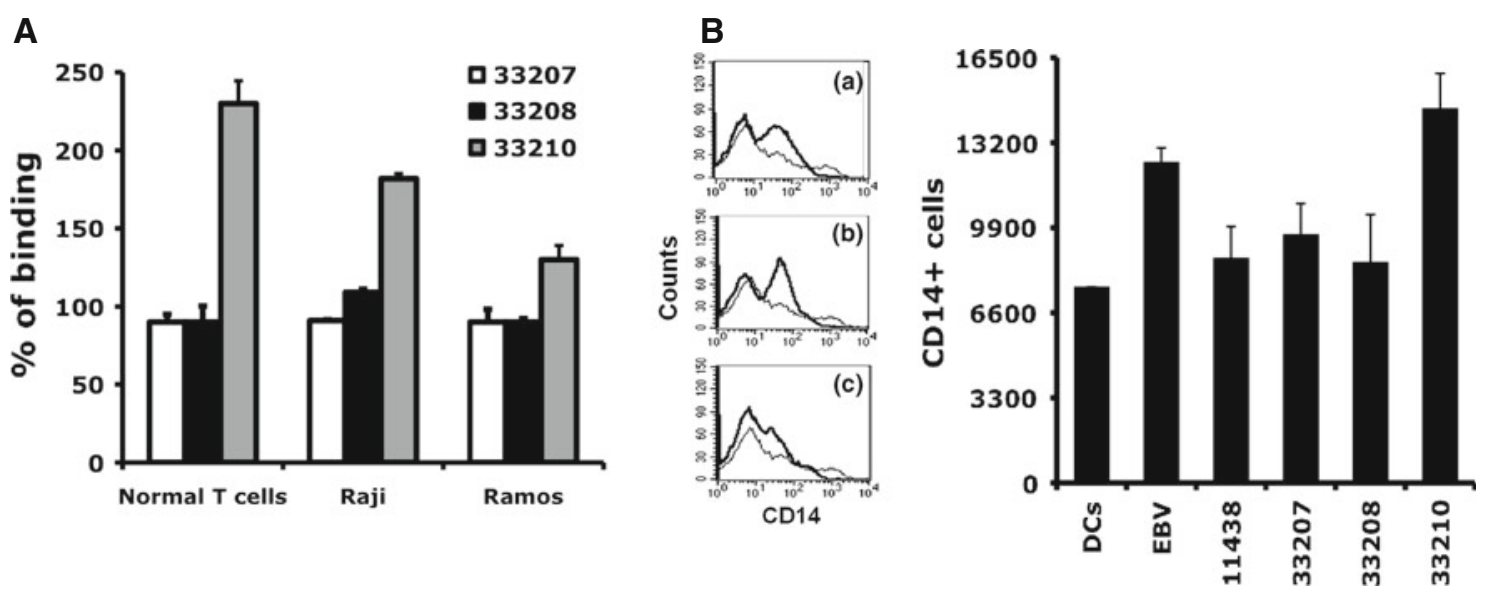

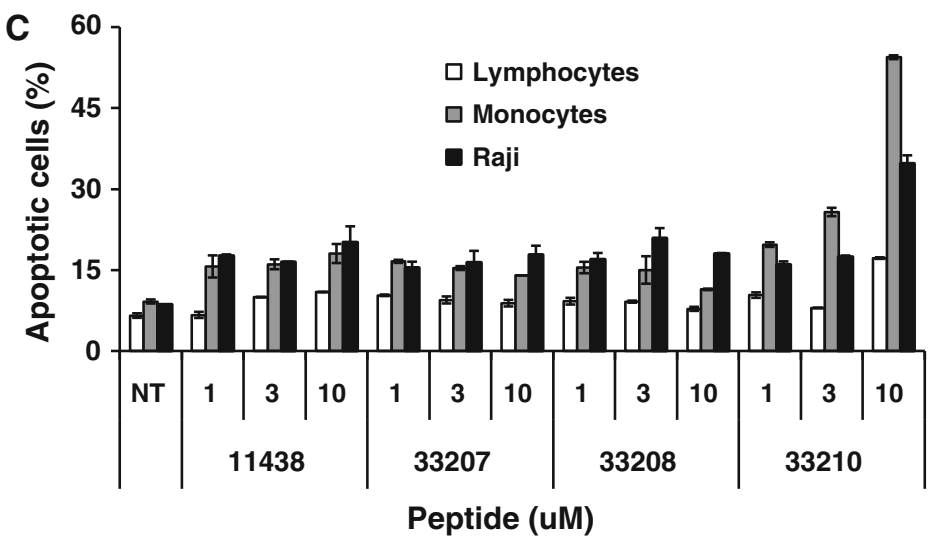

Fig. 5 Capacity of peptides 11438, 33207, 33208 and 33210 to bind to PBMCs, Raji and Ramos cells, their effect in CD14 marker on dendritic cells and apoptosis in T cells, monocytes and Raji cells. a The capacity of peptides to bind to normal $\mathrm{T}$ cells, Raji and Ramos cells was tested by using flow cytometry. The percentage of binding compared with peptide 11438 was calculated as described in "Materials and methods". b CD14 surface expression on monocytes exposed to GM-CSF and IL4 and incubated with EBV, peptides
$11438,33207,33208$ or 33210 . The histogram data represents a typical example of cells not exposed to EBV or peptide (thick line) and exposed (dark line) to: a EBV, b peptide with similar effect to EBV (33210), c peptide without effect (33207). Number of CD14 positive cells shown on the right side. $\mathbf{c}$ Effect of peptides in apoptosis of PBMCs and Raji cells at $10 \mu \mathrm{M}$ concentration. The percentage of apoptotic cells was determined by staining with Annexin V and PI. $N T$ non-treated samples 
Peptide 33210 induced apoptosis in Raji and monocytes but not in $\mathrm{T}$ cells

Taking into account that peptide 33210 was able to bind strongly to T cells and was able to inhibit the development towards dendritic cells, we were interested in its effect on survival or death of these cells as has been described for EBV (Li et al. 2002). Peptides 11438, 33207, 33208 and 33210 were incubated with PBMCs and Raji cells as a control, at different concentrations. The induction of apoptosis was detected by the staining with Annexin V, PI, CD5 and CD14. The result showed that peptide 33210 induced apoptosis in monocytes and Raji cells but not in normal $\mathrm{T}$ cells $(55,38$ and $17 \%$, respectively) at a concentration of $10 \mu \mathrm{M}$ (Fig. 5c).

\section{Discussion}

Peptide 11438 from EBV-gH host cell-binding region inhibits EBV invasion of PBMCs, it is recognized by antiEBV antibodies and is also able to induce antibodies recognizing EBV and EBV-infected cells (Urquiza et al. 2004). This peptide displayed a CD spectrum characteristic of an $\alpha$-helix structure in 30\% TFE, which decreased when TFE concentration was lowered, indicating that this structure was not stable. The aim of this work was to stabilize 11438 peptide's $\alpha$-helix and to determine the effect on its biological activity. Taking into consideration that there is a significant opposing entropy factor in interactions involving peptides (due to high peptide chain mobility) that induce high configurational peptide entropy, our approach lies in reducing configurational peptide's entropy by changing some amino acids to stabilize the $\alpha$-helix and restrict the structures it can acquire in solution.

Peptide 11438 displays low helix stability as a result of high positive unfolding entropy change, suggesting a higher molecular disorder in unfolded than in folded state.

The helical region of peptide 11438 was located in NLKDMFSRA sequence and very likely the $\mathrm{N}$ - and $\mathrm{C}$ -

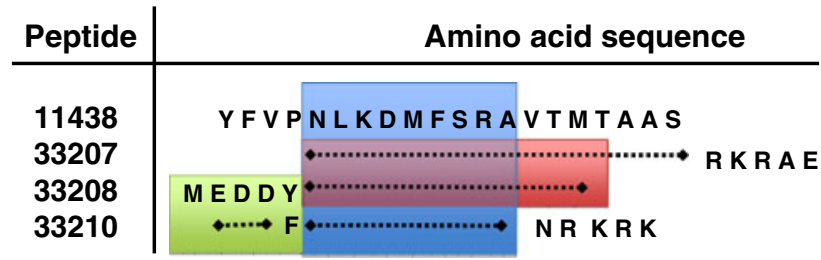

Fig. 6 Representation of peptide 11438 regions and its analogs related to their biological activity. We have found different regions that are important for the binding to the cells (blue-NLKDMFSRA), for keeping the $\alpha$-helix structure (green-YFVP) and for the interaction with the anti-EBV antibodies (red-NLKDMFSRA) terminal regions are not part of the helix; the peptide helical content could be increased by adding basic residues at the C-terminal, probably by stabilizing helix dipole as predicted by AGADIR analysis. The helical content could not be increased by adding residues at the $\mathrm{N}$-terminal because of the presence of 4Pro. On the contrary, the change of 4Pro, insertion of acid residues or the deletion of the residues preceding 4Pro, increased its helical content by stabilizing the helix dipole. This resulted in the design of analog peptides 33208 and 33210 displaying an $\alpha$-helix more stable than peptide 11438 as predicted by using AGADIR and molecular dynamic analysis and determined by CD analysis. In addition, unfolding of these helices was slower than peptide 11438 according to molecular dynamic analysis.

The higher helix stability of peptides 33208 and 33210 was due to a lower unfolding entropy change probably because these peptides in the unfolded state displayed a lower configurational entropy than peptide 11438 in spite of the fact that unfolding enthalpy change (the energy used for breaking the hydrogen bonds) that stabilizes the helices was decreased in peptides 33208 and 33210 . On the contrary, the lower helix stability of peptide 33207 than peptide 11438 , was due to a lower unfolding enthalpy change despite the lower unfolding entropy change. This result showed that some $\alpha$-helix stabilizing interactions were lost in peptide 33207 and could involve hydrophobic interactions mediated by the residues YFV; also that peptide 33207 in the unfolded state displays intra- and/or inter-molecular interactions that stabilize the unfolded state that are not included in the AGADIR calculation. The theoretical $\alpha$-helix of peptide 33207 was very stable by molecular dynamics contrary to the low helical content determined by $\mathrm{CD}$; taking into account that $\mathrm{CD}$ detects the mean peptide's structure in equilibrium a possible explanation could be that helix of peptide 33207 unfolds slowly as determined by molecular dynamics but also folds very slowly in such way that most of the peptide molecules are in an unfolded state.

The biological activity of these peptides in comparison with the native protein present in EBV was tested in the following manner: (1) the ability of anti-EBV sera in recognizing peptides and the ability of anti-peptide sera to bind to EBV; (2) the ability of each peptide and its antisera to inhibit EBV invasion of host cells; (3) the cellbinding activity of the peptide analogs on Raji, Ramos and PBMCs; (4) the ability of peptides to mimic EBV interaction with monocytes by inhibiting its development into dendritic cells; (5) the ability to mimic EBV infection by inducing monocyte apoptosis.

Anti-EBV antibodies showed a higher reactivity against analog peptides 33207, 33208 and 33210 than peptide 11438 suggesting that analog peptides have more similar epitopes to native protein than epitopes on peptide 11438 . The higher anti-EBV reactivity with peptides 33207 and 
33208 than with peptide 11438 strongly suggests that epitope recognized by anti-EBV antibodies is more accessible considering that the EBV-sequence presented in those peptides is contained in peptide 11438. Additionally the reactivity of anti-EBV antibodies against 33208 was higher than with 33207 , despite its sequence being partially contained in peptide 33207; this may be due to its higher helical content, which is three times higher than in peptide 33207. The lower reactivity of anti-EBV antibodies with peptide 33210 (compared with 33207 and 33208 peptides) could be due to the lower helical content of peptide 33210 and the absence of the VTM sequence, which seems to be part of the epitope recognized by anti-EBV antibodies.

All these results suggest that there are B cell epitopes recognized by anti-EBV antibodies in the helical and nonhelical part of these peptides. Moreover, the epitopes on the analog peptides recognized by these antibodies have a more similar structure to native protein than epitopes on peptide 11438 , especially peptide 33208 that displayed the highest helical content and showed the highest reactivity with anti-EBV antibodies. Peptide 33208 could be very helpful for detecting anti-gH antibodies induced by intact EBV.

On the other hand, all these monomeric peptides induced anti-peptide antibodies. Anti-peptide 33207 antibodies showed the highest reactivity with EBV by ELISA in spite of the fact that this peptide displayed the lowest helical content, suggesting that the epitopes inducing these antibodies were located in the non-helical region (containing high proportion of $b$-branched amino acids missing or modified in peptides 33208 and 33210). The low reactivity of the anti-peptide 33210 antibodies with EBV suggests that the VTM region is very important for the induction of antibodies having cross reactivity with EBV. This region could be exposed in peptide 33207 due to the presence of positively charged amino acids (RKRAE) in the C-terminal region. Although this region is also present in peptide 11438 , it could be buried by turn formation and hydrophobic interaction with C-terminal region according to the molecular dynamic analysis. These results show that peptide 33207 would be useful for inducing antibodies that recognize not only EBV infected cells but also EBV intact particles, and also, to study the interaction of $\mathrm{gH}$ with host cells.

Anti-peptide antibodies were capable of inhibiting the EBV invasion of epithelial cells, anti-peptide 33210 antibodies being ten times stronger than the other anti-peptides antibodies in spite of its low reactivity with EBV. This suggests that antibodies induced by peptide 33210 recognized a more critical epitope for EBV invasion that probably is located in its helical region. This is also supported by the fact that peptide 33210 displayed the highest biological activity.
We tested the ability of 11438 analogous peptides in blocking EBV invasion of PBMCs as previously reported(Urquiza et al. 2004); but taking into account that EBV can bind and invade those cells using other proteins such as gp350, we also used epithelial cells (HEK293) (Fingeroth 1999) where gH plays a critical role for EBV invasion. All analogous peptides were able to inhibit EBV invasion of PBMCs and HEK293 at high concentrations $(27 \mu \mathrm{M})$. Only peptide 11438 inhibited EBV invasion of HEK293 at low concentrations $(7 \mu \mathrm{M})$ suggesting that amino acids involved in this interaction are contained in the sequence NLKDMFSRA, which were affected by the changes made at the $\mathrm{C}$ and $\mathrm{N}$-terminal in analogous peptides.

On the other hand, it was found that peptide 33210 was able to bind normal $\mathrm{T}$ cells and Raji cells (B cell line derived from Burkitt lymphoma) which could be mediated by a receptor that is present on both cells or $\mathrm{T}$ cell proteins that are aberrant expressed on B cells (Raji cells) as has been described in chronic lymphocytic leukemia (Stevenson and Caligaris-Cappio 2004).

$\mathrm{gH}$ protein inhibits development towards dendritic cells of monocyte cultured with GM-CSF and IL-4. This process can be followed by detecting changes in CD14 expression because this protein is down regulated or disappears when monocytes mature to dendritic cells. Investigating the peptide 33210 effects on the inhibition of the monocyte development towards dendritic cells, it was found that this peptide induced apoptosis of monocytes, as it was previously described for EBV (Li et al. 2002) but did not induce apoptosis in normal $\mathrm{T}$ cells (to which it binds). The mechanism involved in the apoptosis of monocytes could be due to a direct effect of this peptide or an indirect effect in which $\mathrm{T}$ cells may play a role. The better understanding of the mechanisms involved in this interaction requires further studies.

The biological activity of peptide 11438 that depends on direct binding to cells was not modified in peptides 33207 and 33208 suggesting that the residues YFVP and TAAS from N-terminal and C-terminal regions, respectively, and the helical content of this peptide is not critical for this biological activity. The higher biological activity of peptide 33210 than peptides 11438,33207 and 33208 suggests that the VTM residues, missing in peptide 33210 could be critical for modulating its activity and/or the sequence added to C-terminal increased its biological activity by inducing additional contacts that make the peptide interaction stronger with the cell (Fig. 6).

The changes performed on peptide 11438 decreased the change in unfolding entropy that resulted in higher $\alpha$-helix stability of peptides 33208 and 33210. However, drastic decreases in unfolding enthalpy change resulted in an opposite effect by decreasing the $\alpha$-helix stability as it was 
shown in peptide 33207. Interestingly the biological activity was modulated by these changes that are not necessarily associated with the helical content. The increase in the helix stability increased the reactivity with anti-EBV antibodies as was seen in peptide 33208; it also showed that anti-peptide antibodies (peptide 33210) directed towards the $\alpha$-helix were able to neutralize the EBV infection to host cells.

Interestingly, we have designed peptide 33210 which presented the highest binding activity, induction of apoptosis in monocyte and the arrest of maturation of dendritic cells.

In general, these results showed that it is possible to modulate not only the antigenicity and immunogenicity but also the biological activity of peptide 11438 by modifying the $\alpha$-helix stability and the amino acid sequence. Peptides 33207, 33208 and 33210 will be useful to understand the mechanism behind the molecular interactions between the cells and $\mathrm{gH}$.

Acknowledgments We specially thank Jason Garry for translating the manuscript. This research was supported by the Colombian President's office and the Instituto Colombiano para el desarrollo de la Ciencia y la Tecnologia Francisco Jose de Caldas (COLCIENCIAS) contract RC-2009.

Open Access This article is distributed under the terms of the Creative Commons Attribution Noncommercial License which permits any noncommercial use, distribution, and reproduction in any medium, provided the original author(s) and source are credited.

\section{References}

Bax A, Davis DG (1985) MLEV-17-based two-dimensional homonuclear magnetization transfer spectroscopy. J Magn Reson 65:355-360

Borza C, Hutt-Fletcher L (2002) Alternate replication in B cells and epithelial cells switches tropism of Epstein-Barr virus. Nat Med 8:594-599

Chen P, Pan CC, Yang AH, Wang LS, Chiang H (2002) Detection of Epstein-Barr virus genome within thymic epithelial tumours in Taiwanese patients by nested PCR, PCR in situ hybridization, and RNA in situ hybridization. J Pathol 197:684-688

Chesnokova LS, Nishimura SL, Hutt-Fletcher LM (2009) Fusion of epithelial cells by Epstein-Barr virus proteins is triggered by binding of viral glycoproteins $\mathrm{gHgL}$ to integrins alphavbeta6 or alphavbeta8. Proc Natl Acad Sci USA 106:20464-20469

Delves PJ (1997) Antibody production: essential techniques. Wiley and Sons, Chichester, NY

De-The G, Zeng Y (1982) Epidemiology of Epstein-Barr virus: recent results on endemic vs. non-endemic Burkitt's lymphoma and EBV related pre-nasopharyngeal carcinoma conditions. In: Yohn OS, Blakeslee JR (eds) Advances in comparative leukemia research. Elsevier, New York

Fingeroth JD, Diamond ME, Sage DR, Hayman J, Yates JL (1999) CD21-dependent infection of an epithelial cell line, 293, by Epstein-Barr virus. J Virol 73:2115-2125
Garnier J, Gibrat JF, Robson B (1996) GOR method for predicting protein secondary structure from amino acid sequence. Methods Enzymol 266:540-553

Haddad R, Hutt-Fletcher L (1989) Depletion of glycoprotein gp85 from virosomes made with Epstein-Barr virus proteins abolishes their ability to fuse with virus receptor-bearing cells. J Virol 63:4998-5005

Harada S, Sakamoto K, Seeley J, Lindsten T, Bechtold T, Yetz J, Rogers G, Pearson G, Purtilo D (1982) Immune deficiency in the $\mathrm{X}$-linked lymphoproliferative syndrome I. Epstein-Barr virusspecific defects. J Immunol 129:2532-2535

Henle G, Henle W, Diehl Y (1968) Relation of Burkitt's tumor associated herpes-type virus to infectious mononucleosis. Proc Natl Acad Sci 59:94-101

Houghten RA (1985) General method for the rapid solid-phase synthesis of large numbers of peptides: specificity of antigenantibody interaction at the level of individual amino acids. Proc Natl Acad Sci USA 82:5131-5135

Huang D, Ho J, Henle W, Henle G (1974) Demonstration of EpsteinBarr virus-associated nuclear antigen in nasopharyngeal carcinoma cells from fresh biopsies. Int J Cancer 14:580-588

Jeener J, Meier BH, Bachman P, Ernts RR (1979) Investigation of exchange processes by two-dimensional NMR spectroscopy. J Chem Phys 71:4546-4553

Li Q, Spriggs M, Kovats S, Turk SM, Comeau MR, Nepom B, HuttFletcher LM (1997) Epstein-Barr virus uses HLA class II as a cofactor for infection of B lymphocytes. J Virol 71:4657-4662

Li L, Hutt Fletcher L, Morgan A, Masucci M, Levitsky V (2002) Epstein-Barr virus inhibits the development of dendritic cells by promoting apoptosis of their monocyte precursors in the presence of granulocyte macrophage-colony stimulating factor and interleukin-4. Blood 99:3725-3733

Miller N, Hutt-Fletcher L (1988) A monoclonal antibody to glycoprotein gp85 inhibits fusion but not attachment of Epstein-Barr virus. J Virol 62:2366-2372

Molesworth S, Lake C, Borza C, Turk S, Hutt-Fletcher L (2000) Epstein-Barr virus $\mathrm{gH}$ is essential for penetration of $\mathrm{B}$ cells but also plays a role in attachment of virus to epithelial cells. J Virol 74:6324-6332

Montagnier L, Gruest J, Chamaret S, Dauguet C, Axler C, Guetard D, Nugeyre M, Barre-Sinoussi F, Chermann J, Brunet J (1984) Adaptation of lymphadenopathy associated virus to replication in EBV-transformed B lymphoblastoid cell lines. Science 225:6366

Muñoz V, Serrano L (1997) Development of the multiple sequence approximation within the Agadir Model of $\alpha$-helix formation comparison with Zimm-Bragg and Lifson-Roig formalisms. Biopolymers 41:495-509

Nemerow G, Houghten R, Moore M, Cooper N (1989) Identification of an epitope in the major envelope protein of Epstein-Barr virus that mediates viral binding to the B lymphocyte EBV receptor (CR2). Cell 56:369-377

Omerovic J, Lev L, Longnecker R (2005) The amino terminus of Epstein-Barr virus glycoprotein $\mathrm{gH}$ is important for fusion with epithelial and B cells. J Virol 79:12408-12415

Pelicci P, Knowles M II, Arlin Z, Wieczorek R, Luciw P, Dina D, Basilico C, Dalla-Favera R (1986) Multiple monoclonal B cell expansions and c-myc oncogene rearrangements in acquired immune deficiency syndrome-related lymphoproliferative disorders Implications for lymphoma genesis. J Exp Med 164:20492060

Prieto I, Hervás-Stubbs S, García-Granero M, Berasain C, Riezu-Boj JI, Lasarte JJ, Sarobe P, Prieto J, Borrás-Cuesta F (1995) Simple strategy to induce antibodies of distinct specificity: application to the mapping of gp120 and inhibition of HIV-1 infectivity. Eur J Immunol 25:877-883 
Provencher S, Glockner J (1981) Estimation of globular protein secondary structure from circular dichroism. Biochemistry 20:33-37

Raab-Traub R, Flynn G, Pearson A, Huang P, Levine A, Lanier J, Pagano J (1987) The differentiated form of nasopharyngeal carcinoma contains Epstein-Barr virus DNA. Int J Cancer 39:25-29

Rance M, Soressen OW, Bodenhausen G, Wagner G, Ernst RR, Wüthrich K (1983) Improved spectral resolution in cosy $1 \mathrm{H}$ NMR spectra of proteins via double quantum filtering. Biochem Biophys Res Commun 117:419-485

Spriggs M, Armitage R, Comeau M, Strockbine L, Farrah T, Macduff B, Ulrich D, Alderson M, Mullberg J, Cohen J (1996) The extracellular domain of the Epstein-Barr virus BZLF2 protein binds the HLA-DR beta chain and inhibits antigen presentation. J Virol 70:5557-5563

Stevenson FK, Caligaris-Cappio F (2004) Chronic lymphocytic leukemia: revelations from the B-cell receptor. Blood 103: 4389-4395

Tam J, Heath WF, Merrifield RB (1983) SN 1 and SN 2 mechanisms for the deprotection of synthetic peptides by hydrogen fluoride.
Studies to minimize the tyrosine alkylation side reaction. Int $\mathbf{J}$ Pept Protein Res 21:57-65

Tanner J, Weis J, Fearon D, Whang Y, Kieff E (1987) Epstein-Barr virus gp350/220 binding to the $\mathrm{B}$ lymphocyte $\mathrm{C} 3 \mathrm{~d}$ receptor mediates adsorption, capping, and endocytosis. Cell 50:203-213

Urquiza M, Suarez J, Lopez R, Vega E, Patino H, Garcia J, Patarroyo M, Guzman F, Patarroyo M (2004) Identifying gp85-regions involved in Epstein-Barr virus binding to B-lymphocytes. Biochem Biophys Res Commun 319:221-229

Wang X, Kenyon J, Li Q, Mullberg J, Hutt-Fletcher L (1998) Epstein-Barr virus uses different complexes of glycoproteins $\mathrm{gH}$ and $\mathrm{gL}$ to infect $\mathrm{B}$ lymphocytes and epithelial cells. J Virol 72:5552-5558

Yarchoan R, Redfield R, Broder S (1986) Mechanisms of B cell activation in patients with acquired immunodeficiency syndrome and related disorders. Contribution of antibody-producing $\mathrm{B}$ cells, of Epstein-Barr virus-infected B cells, and of immunoglobulin production induced by human $\mathrm{T}$ cell lymphotropic virus, type III/lymphadenopathy-associated virus. J Clin Invest 78:439-447 